\title{
Intramuscular variation in mitochondrial functionality of beef semimembranosus
}

\author{
M.N. Nair ${ }^{1}$, R. Ramanathan ${ }^{2}$, G. Rentfrow ${ }^{3}$, \& S.P. Suman ${ }^{3, \#}$ \\ ${ }^{1}$ Department of Animal Sciences, Colorado State University, Fort Collins, Co 80523, USA \\ ${ }^{2}$ Department of Animal Science, Oklahoma State University, Stillwater, OK 74078, USA \\ ${ }^{3}$ Department of Animal and Food Sciences, University of Kentucky, Lexington, KY 40546, USA
}

(Received 1 June 2017; Accepted 31 July 2017; First published online 16 August 2017)

Copyright resides with the authors in terms of the Creative Commons Attribution 4.0 South African License.
See: http://creativecommons.org/licenses/by/4.0/za
Condition of use: The user may copy, distribute, transmit and adapt the work, but must recognize the authors and the South African Journal
of Animal Science.

\begin{abstract}
Intramuscular color stability variations in beef semimembranosus have been reported previously. Mitochondria remain biochemically active in postmortem muscle and can influence fresh beef color stability. However, the role of mitochondrial functionality in intramuscular color variations in beef semimembranosus is yet to be examined. We examined the functionality of mitochondria isolated from outside (OSM) and inside (ISM) regions of beef semimembranosus. Semimembranosus muscles $(n=5)$ were collected from inside rounds of beef carcasses $48 \mathrm{~h}$ post-mortem and were separated to OSM and ISM steaks. Color attributes were evaluated instrumentally and biochemically on days 0 and 4 of retail display, whereas mitochondrial oxygen consumption rate (OCR) was measured on day 0 using succinate as substrate using steaks frozen during fabrication. Mitochondrial OCR was significantly greater in OSM than in ISM on day 0 . The ISM steaks exhibited significantly greater redness ( $a^{*}$ value) than OSM steaks on day 0 , but OSM steaks had significantly greater redness than the ISM counterparts on day 4 . During retail display, ISM steaks exhibited greater lightness ( $L^{*}$ value) than OSM steaks. However, OSM demonstrated significantly greater color stability and metmyoglobin reducing activity than ISM throughout the display. The observed differences in mitochondrial OCR between ISM and OSM steaks indicated that mitochondrial biochemistry possibly contributes to the intramuscular color variations in beef semimembranosus.
\end{abstract}

Keywords: Beef color, color stability, mitochondria, semimembranosus

\#Corresponding author: spsuma2@uky.edu

\section{Introduction}

Fresh meat color critically influences consumer purchase decisions (Suman et al., 2014), and the annual revenue loss to the United States beef industry due to discoloration is estimated to be more than 1 billion USD (Smith et al., 2000). Beef color and color stability are muscle-specific traits (McKenna et al., 2005; Von Seggern et al., 2005). Large beef muscles such as semimembranosus (Sammel et al., 2002a) and biceps femoris (Pastsart et al., 2013) exhibit intramuscular variations in color stability. Beef semimembranosus can be separated into color-stable outside (OSM) and color-labile inside (ISM) regions based on the location within the carcass. The variation in color has been partly attributed to differences in temperature and $\mathrm{pH}$ decline during carcass chilling (Sammel et al., 2002a). Further research indicated that differential abundance of sarcoplasmic proteome could also result in rapid pH fall and compromise color stability of ISM (Nair et al., 2016).

Myoglobin is the sarcoplasmic heme protein responsible for meat color, and the interactions between myoglobin and cellular components govern color biochemistry (Suman \& Joseph, 2013; Suman \& Nair, 2017). Mitochondria remain biochemically active in postmortem muscle and may influence the bloom development and color stability by competing with myoglobin for available oxygen and by providing reducing equivalents for metmyoglobin reduction (Ashmore et al., 1972; Tang et al., 2005a, 2005b). Furthermore, Belskie et al. (2015a) reported muscle-specificity in beef mitochondrial biochemistry, with color-labile psoas major demonstrating rapid decrease in mitochondrial oxygen consumption rate (OCR) compared to color-stable longissimus dorsi. However, intramuscular variation in functionality of mitochondria and its relationship with color biochemistry are 
yet to be examined. Therefore, the objective of the present study was to examine the functionality of mitochondria isolated from beef OSM and ISM.

\section{Materials and Methods}

Carcasses obtained from beef cattle of unknown backgrounds were utilized in this study in an attempt to effectively simulate commercial market scenario in the United States beef industry. Beef inside rounds (USDA Select grade; IMPS \# 168) from five carcasses $(n=5)$ were obtained from a commercial packing plant $48 \mathrm{~h}$ postmortem. The cuts were vacuum packaged in the plant and transported under refrigeration to the USDAinspected meat laboratory at University of Kentucky, where the semimembranosus muscle was separated and fabricated into $2.54 \mathrm{~cm}$ OSM and ISM steaks. Each muscle was fabricated to seven OSM and seven ISM steaks. One steak was vacuum packaged and frozen immediately at $-80^{\circ} \mathrm{C}$ for mitochondria isolation, whereas the six other steaks were individually placed on Styrofoam trays and aerobically overwrapped with oxygen-permeable polyvinyl chloride film $\left(15,500-16,275 \mathrm{~cm}^{3} / \mathrm{m}^{2} / 24 \mathrm{~h}\right.$ oxygen transmission rate at $\left.23^{\circ} \mathrm{C}\right)$. The steaks were assigned randomly for refrigerated retail display $\left(2^{\circ} \mathrm{C}\right)$ under constant, cool white fluorescent lighting (1300 lx) for 0 or 4 days and were utilized for evaluation of instrumental color and biochemical traits.

On day 0 of retail display, the instrumental color attributes were evaluated after allowing the steaks to bloom for $2 \mathrm{~h}$ at $2^{\circ} \mathrm{C}$ after fabrication, whereas on day 4 of display the measurements were taken on the lightexposed steak surfaces. A HunterLab LabScan XE colorimeter (Hunter Associates Laboratory, Reston, VA, USA) with $2.54 \mathrm{~cm}$ diameter aperture, illuminant $A$, and $10^{\circ}$ standard observer was used to measure CIE lightness $\left(L^{*}\right)$, redness $\left(a^{*}\right)$, yellowness $\left(b^{*}\right)$, hue (trueness of red), and chroma (saturation index) values on from three random locations on the steak surfaces (AMSA, 2012). Standard black and white plates were used for calibrating the colorimeter. In addition, the ratio of reflectance at $630 \mathrm{~nm}$ and $580 \mathrm{~nm}(\mathrm{R} 630 / 580)$ was calculated to estimate the surface color stability of steaks; greater ratio indicates lesser amount of metmyoglobin and thus greater color stability (AMSA, 2012).

The $\mathrm{pH}$ of steaks was determined according to the method of Strange et al. (1977) using an Accumet AR25 pH-meter (Fisher Scientific, Pittsburgh, PA, USA). Duplicate $5 \mathrm{~g}$ samples were homogenized in $30 \mathrm{~mL}$ distilled deionized water before measuring the $\mathrm{pH}$.

Thiobarbituric acid assay was employed for measuring the lipid oxidation (Yin et al., 1993). Briefly, duplicate $5 \mathrm{~g}$ samples were homogenized with $11 \%$ trichloroacetic acid in a blender. The homogenate was then filtered using Whatman No. 1 filter paper. One $\mathrm{mL}$ of filtrate was mixed with $1 \mathrm{~mL}$ of aqueous thiobarbituric acid $(20 \mathrm{mM})$ and incubated at $25^{\circ} \mathrm{C}$ for $20 \mathrm{~h}$. The absorbance of samples at $532 \mathrm{~nm}$ measured spectrophotometrically (UV-2401 spectrophotometer, Shimadzu Inc., Columbia, MD, USA) were reported as thiobarbituric acid reactive substances (TBARS).

Metmyoglobin reducing activity (MRA) was evaluated according to the method described by Sammel et al. (2002b). Cubes $\left(2.5 \times 2.5 \times 2.5 \mathrm{~cm}^{3}\right)$ of meat were removed from the light-exposed surfaces. Metmyoglobin formation was induced in the samples by submerging them in a solution of $0.3 \%$ sodium nitrite for 20 min at room temperature. After $20 \mathrm{~min}$, samples were removed from the solution, blotted dry, vacuum packaged. The reflectance spectra from 700 to $400 \mathrm{~nm}$ were recorded on the light-exposed surface using a HunterLab LabScan XE colorimeter. The vacuum-packaged samples were then incubated at $30{ }^{\circ} \mathrm{C}$ for $2 \mathrm{~h}$ to induce reduction of metmyoglobin. The reflectance spectra from 700 to $400 \mathrm{~nm}$ were recorded again at the end of incubation. Percentage of pre- and post- incubation surface metmyoglobin was calculated based on K/S ratios and according to established formulas (AMSA, 2012). MRA was calculated using the following equation:

MRA $=100 \times[(\%$ pre-incubation surface metmyoglobin - \% post-incubation surface metmyoglobin $) / \%$ pre-incubation surface metmyoglobin]

Mitochondria were isolated from OSM and ISM steaks frozen during fabrication (on day 0 ) according to Lanari \& Cassens (1991), with minor modifications. Finely minced meat $(35 \mathrm{~g})$ was suspended in $70 \mathrm{~mL}$ mitochondria suspension buffer (250mM Sucrose, $10 \mathrm{mM}$ HEPES, $\mathrm{pH}$ 7.2). The suspension was stirred slowly and hydrolyzed with trypsin ( $1 \mathrm{mg} / \mathrm{g}$ of tissue) for $15 \mathrm{~min}$. After proteolytic digestion, the suspension was diluted to $350 \mathrm{~mL}$ with mitochondria isolation buffer $(67 \mathrm{mM}$ sucrose, $50 \mathrm{mM}$ Tris- $\mathrm{HCl}, 50 \mathrm{mM} \mathrm{KCl}, 10 \mathrm{mM}$ EDTA, and $0.2 \% \mathrm{BSA}, \mathrm{pH}$ 7.2) and homogenized using a Kontes Duall grinder (Vineland, NJ) followed by a Wheaton PotterElvehjem grinder (Millville, NJ). The homogenate was centrifuged at $900 \times \mathrm{g}$ for $15 \mathrm{~min}$ with a Sorvall refrigerated RC-5C plus centrifuge (Thermo Fisher Scientific, Newtown, CT), and the resulting supernatant was again centrifuged at $14000 \times \mathrm{g}$ for $15 \mathrm{~min}$. Mitochondrial pellets obtained were washed twice and suspended in 
mitochondria suspension buffer. All steps were performed at $0-4{ }^{\circ} \mathrm{C}$. Mitochondrial protein content was determined using a bicinchoninic acid protein assay.

Mitochondrial oxygen consumption rate (OCR) was measured using a Clark electrode attached to a Rank Brothers digital model 20 oxygen controller (Cambridge, England). Oxygen consumption was recorded over time

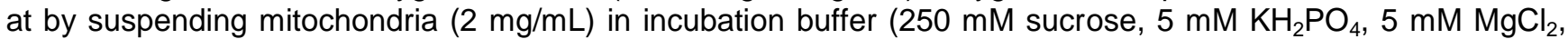
$0.1 \mathrm{mM}$ EDTA, $0.1 \% \mathrm{BSA}$, and $20 \mathrm{mM}$ maleic acid) in the Clark oxygen electrode with the addition of succinate $(40 \mathrm{mM})$ at $\mathrm{pH} 5.6$ and $25^{\circ} \mathrm{C}$. The chamber was stirred with a $10 \mathrm{~mm}$ magnetic bar at $600 \mathrm{rpm}$. Following the addition of substrate, oxygen consumption per mg of mitochondria from each muscle was calculated based on the method of Estabrook (1967).

The experimental design was a randomized complete block design, where each carcass $(n=5)$ served as a block. The effects of muscle location (ISM and OSM), storage (0 and 4 days), and their interactions on color and other biochemical parameters were analyzed using the Mixed Procedure of SAS. Least square means for protected $\mathrm{F}$-tests $(P<0.05)$ were separated by using least significant differences and were considered significant at $P<0.05$.

\section{Results and Discussion}

The results of instrumental color and biochemical attributes are presented in Table 1.

Table 1 Instrumental color, biochemical attributes, and mitochondrial oxygen consumption rate (OCR) of beef inside (ISM) and outside (OSM) semimembranosus steaks $(n=5)$ during refrigerated retail display $\left(2{ }^{\circ} \mathrm{C}\right)$ for 4 days under aerobic packaging (Mean $\pm \mathrm{SE}$ )

\begin{tabular}{|c|c|c|c|}
\hline \multirow{2}{*}{ Attribute } & \multirow[b]{2}{*}{ Muscle } & \multicolumn{2}{|c|}{ Retail display days } \\
\hline & & 0 & 4 \\
\hline \multirow{2}{*}{$L^{*}$ value } & ISM & $49.51^{\mathrm{ax}} \pm 1.36$ & $46.93^{\mathrm{ax}} \pm 1.50$ \\
\hline & osm & $39.81^{\text {ay }} \pm 1.41$ & $39.86^{\mathrm{ay}} \pm 0.68$ \\
\hline \multirow{2}{*}{$a^{*}$ value } & ISM & $35.74^{a x} \pm 0.34$ & $22.83^{\text {by }} \pm 0.85$ \\
\hline & osm & $33.10^{\text {ay }} \pm 0.37$ & $26.69^{b x} \pm 0.50$ \\
\hline \multirow{2}{*}{$b^{*}$ value } & ISM & $27.75^{a x} \pm 0.37$ & $19.71^{b x} \pm 0.28$ \\
\hline & OSM & $24.94^{\text {ay }} \pm 0.50$ & $20.73^{b x} \pm 0.43$ \\
\hline \multirow{2}{*}{ Chroma } & ISM & $45.25^{\mathrm{ax}} \pm 0.49$ & $29.84^{\text {by }} \pm 0.71$ \\
\hline & OSM & $41.45^{\text {ay }} \pm 0.57$ & $33.57^{b x} \pm 0.47$ \\
\hline \multirow{2}{*}{ Hue } & ISM & $37.82^{\mathrm{ax}} \pm 0.14$ & $30.71^{b x} \pm 0.79$ \\
\hline & OSM & $36.99^{a x} \pm 0.35$ & $33.80^{\text {by }} \pm 0.65$ \\
\hline \multirow{2}{*}{$\mathrm{R} 630 / 580$} & ISM & $5.87^{\mathrm{ay}} \pm 0.24$ & $2.63^{\text {by }} \pm 0.17$ \\
\hline & OSM & $6.88^{\mathrm{ax}} \pm 0.36$ & $3.93^{b x} \pm 0.16$ \\
\hline \multirow{2}{*}{ MRA } & ISM & $27.17^{\text {ay }} \pm 1.86$ & $4.96^{\text {by }} \pm 1.95$ \\
\hline & OSM & $62.61^{\mathrm{ax}} \pm 1.55$ & $34.13^{b x} \pm 2.10$ \\
\hline \multirow{2}{*}{$\mathrm{pH}$} & ISM & $5.38^{b x} \pm 0.01$ & $5.42^{\mathrm{ax}} \pm 0.01$ \\
\hline & OSM & $5.36^{\mathrm{bx}} \pm 0.01$ & $5.40^{\mathrm{ax}} \pm 0.01$ \\
\hline \multirow{2}{*}{ TBARS } & ISM & $0.016^{b x} \pm 0.002$ & $0.108^{a x} \pm 0.034$ \\
\hline & OSM & $0.016^{b x} \pm 0.001$ & $0.113^{a x} \pm 0.022$ \\
\hline \multirow{2}{*}{ Mitochondrial $\mathrm{OCR}^{\Psi}$} & ISM & $16.89^{\mathrm{y}} \pm 2.13$ & NA \\
\hline & OSM & $41.18^{x} \pm 8.22$ & NA \\
\hline
\end{tabular}


ISM exhibited greater $(P<0.05)$ redness $\left(a^{*}\right.$ value) than OSM after $2 \mathrm{~h}$ of blooming on day 0 . However, by day 4 of display, this trend reversed, and the OSM steaks had greater $(P<0.05)$ redness that their ISM counterparts, indicating that OSM is more color stable compared to ISM. Our results are in agreement with previous studies which also reported greater $a^{*}$ values for ISM than OSM on day 0 of display, and a similar reversal of redness with OSM having greater redness for rest of the display days (Sammel et al., 2002b, Nair et al., 2016). As anticipated, the redness of both ISM and OSM steaks decreased $(P<0.05)$ during retail display.

Throughout the display, ISM demonstrated greater $(P<0.05)$ lightness $\left(L^{*}\right.$ value) compared to OSM, and it is one of the most visually appreciable difference in color between ISM and OSM. ISM had greater $(P<0.05)$ yellowness $\left(b^{*}\right.$ value) than OSM on day 0 , whereas ISM and OSM had similar $(P>0.05) b^{*}$ value on day 4 . Similar to $a^{*}$ value, chroma was greater $(P<0.05)$ in ISM on day 0 , and in OSM on day 4 of display. In the present study, hue angle (trueness of red) was similar $(P>0.05)$ between ISM and OSM on day 0, and OSM had greater $(P<0.05)$ hue angle by end of display, as documented in earlier studies (Sammel et al., 2002a, Nair et al., 2016). The OSM steaks in the current study demonstrated greater $(P<0.05)$ color stability $(\mathrm{R} 630 / 580)$ and MRA than their ISM counterparts throughout display days, which indicated that OSM is color-stable muscle whereas ISM is color-labile. In support, Sammel et al. (2002b) and Nair et al. (2016) also reported a similar trend with color stability and MRA in OSM and ISM. In partial agreement, Pastsart et al. (2013) reported intramuscular variation in color stability of biceps femoris from double-muscled Belgian Blue cattle. Lipid oxidation and $\mathrm{pH}$ were similar $(P>0.05)$ for OSM and ISM and is in agreement with that of Nair et al. (2016). In general, our results on color parameters are in agreement with previous research (Sammel et al., 2002a; Nair et al., 2016) and confirm the intramuscular variation in color and color stability of beef semimembranosus.

Mitochondrial OCR, indicative of mitochondrial functionality, was lower $(P<0.05)$ in ISM than OSM. In support, Sammel et al. (2002b) reported lower oxygen consumption in ISM when measured directly from muscle samples and suggested that the lower oxygen consumption of ISM allowed more oxygen penetration into the muscle resulting in improved bloom. Mitochondrial functionality and myoglobin chemistry are interrelated (Wittenberg \& Wittenberg, 2007). Active mitochondria could out-compete myoglobin for the available oxygen leading to low oxygen availability for formation of cherry-red oxymyoglobin (i.e. bloom development). The lower mitochondrial OCR in ISM could facilitate greater oxygen availability for myoglobin oxygenation resulting in greater blooming and initial redness in ISM, as observed in the present study.

Active mitochondria can also provide reducing equivalents for metmyoglobin reduction, a process critical in maintaining color stability during retail display (Arihara et al., 1995; Tang et al., 2005a). Moreover, mitochondria can regenerate $\mathrm{NADH}$, which can be utilized for metmyoglobin reduction through electron transport-mediated and enzymatic pathways (Belskie et al., 2015b). OSM, which demonstrated greater $(P<0.05)$ mitochondrial OCR than ISM, had greater $(P<0.05)$ redness on day 4 as well as greater $(P<0.05)$ color stability (R630/580) and MRA throughout the display. Furthermore, Belskie et al. (2015a) reported that mitochondria from color-stable longissimus dorsi steaks demonstrated greater activity than those from color-labile psoas major on days 5 and 7 of display resulting in improved color stability for longissimus dorsi steaks. These results, along with the observations in the present study, highlight the critical role of mitochondrial functionality in beef color stability.

\section{Conclusion}

The results of the present study indicated the existence of intramuscular variation in mitochondrial functionality in beef semimembranosus. ISM exhibited lower mitochondrial OCR and greater initial redness, whereas OSM demonstrated greater $(P<0.05)$ redness at the end of retail display as well as greater mitochondrial OCR and color stability throughout the display. These results suggested that the variations in mitochondrial biochemistry (between ISM and OSM) could be partially responsible for the intramuscular color variations in beef semimembranosus.

\section{Acknowledgements}

This is publication number 17-07-050 of the Kentucky Agricultural Experiment Station and is published with the approval of the director. This work is supported by the National Institute of Food and Agriculture, U.S. Department of Agriculture, Hatch-Multistate Project 1008755.

\section{Authors' Contributions}


Conception and design - MNN \& SPS; Data collection and analyses - MNN, RR, \& GR; Drafting of paper - MNN; Critical revision and final approval of version to be published - SPS.

\section{Conflict of Interest Declaration}

The authors declare that they have no affiliations with any organization or entity with any financial or non-financial interest that could bias the subject matter and outcomes discussed in this manuscript.

\section{References}

AMSA., 2012. Meat color measurement guidelines. American Meat Science Association. Champaign, IL, USA.

Arihara, K., Cassens, R.G., Greaser, M.L., Luchansky, J.B. \& Mozdziak, P. E., 1995. Localization of metmyoglobin-reducing enzyme (NADH-cytochrome b5 reductase) system components in bovine skeletal muscle. Meat Sci. 39, $205-213$.

Ashmore, C.R., Parker, W. \& Doerr, L., 1972. Respiration of mitochondria isolated from dark-cutting beef: postmortem changes. J. Anim. Sci. 34, 46-48.

Belskie, K M., Van Buiten, C.B., Ramanathan, R. \& Mancini, R.A., 2015b. Reverse electron transport effects on NADH formation and metmyoglobin reduction. Meat Sci. 105, 89-92.

Belskie, K.M., Ramanathan, R., Suman, S.P. \& Mancini, R.A., 2015a. Effects of muscle type and display time on beef mitochondria. Meat Sci. 101, 157-158.

Estabrook, R.W., 1967. Mitochondrial respiratory control and the polarographic measurement of ADP: O ratios. Methods Enzymol. 10, 41-47.

Lanari, M.C. \& Cassens, R.G., 1991. Mitochondrial activity and beef muscle color stability. J Food Sci. 56, $1476-1479$.

McKenna, D.R., Mies, P.D., Baird, B.E., Pfeiffer, K.D., Ellebracht, J.W. \& Savell, J.W., 2005. Biochemical and physical factors affecting discoloration characteristics of 19 bovine muscles. Meat Sci. 70, 665-682.

Nair, M.N., Suman, S.P., Chatli, M.K., Li, S., Joseph, P., Beach, C.M. \& Rentfrow. G., 2016. Proteome basis for intramuscular variation in color stability of beef semimembranosus. Meat Sci. 113, 9-16.

Pastsart, U., De Boever, M., Claeys, E., \& De Smet, S., 2013. Effect of muscle and post-mortem rate of pH and temperature fall on antioxidant enzyme activities in beef. Meat Sci. 93, 681-686.

Sammel, L.M., Hunt, M.C., Kropf, D.H., Hachmeister, K.A., Kastner, C.L \& Johnson, D.E., 2002a. Influence of chemical characteristics of beef inside and outside semimembranosus on color traits. J Food Sci. 67, 1323-1330.

Sammel, L.M., Hunt, M.C., Kropf, D.H., Hachmeister, K.A. \& Johnson, D.E., 2002b. Comparison of assays for metmyoglobin reducing ability in beef inside and outside semimembranosus muscle. J Food Sci. 67, 978-984.

Smith, G.C., Belk, K.E., Sofos, J.N., Tatum, J.D. \& Williams, S.N., 2000. Economic implications of improved color stability in beef. In Antioxidants in muscle foods: Nutritional strategies to improve quality, ed.by Decker, E. A., Faustman, C, \& Lopez-Bote, C. J. Wiley Interscience, New York. Pp. 397-426.

Strange, E.D., Benedict, R.C., Smith, J.L. \& Swift, C.E., 1977. Evaluation of rapid tests for monitoring alterations in meat quality during storage: I. Intact meat. J Food Prot. 12, 820-872.

Suman, S. P. \& Joseph, P., 2013. Myoglobin chemistry and meat color. Annu Rev. Food Sci. Technol. 4, 79-99.

Suman, S.P., Hunt, M.C., Nair, M.N. \& Rentfrow, G., 2014. Improving beef color stability: Practical strategies and underlying mechanisms. Meat Sci. 98, 490-504.

Suman, S.P. \& Nair, M.N., 2017. Current developments in fundamental and applied aspects of meat color. In New Aspects of Meat Quality: From Genes to Ethics. Edited by P.P. Purslow. Elsevier, Oxford, United Kingdom. Chapter 6, pp 115127.

Tang, J., Faustman, C., Hoagland, T.A., Mancini, R.A., Seyfert, M. \& Hunt, M.C. 2005a. Postmortem oxygen consumption by mitochondria and its effects on myoglobin form and stability. J Agric. Food Chem. 53, 1223-1230.

Tang, J., Faustman, C., Mancini, R.A., Seyfert, M. \& Hunt, M.C., 2005b. Mitochondrial reduction of metmyoglobin: Dependence on the electron transport chain. J Agric. Food Chem. 53, 5449-5455.

Von Seggern, D.D., Calkins, C.R., Johnson, D.D., Brickler, J.E. \& Gwartney, B.L., 2005. Muscle profiling: Characterizing the muscles of the beef chuck and round. Meat Sci., 71, 39-51.

Wittenberg, J.B. \& Wittenberg, B.A., 2007. Myoglobin-enhanced oxygen delivery to isolated cardiac mitochondria. J Exp. Biol. 210, 2082-2090.

Yin, M.C., Faustman, C., Riesen, J.W. \& Williams, S.N., 1993. a-Tocopherol and ascorbate delay oxymyoglobin and phospholipid oxidation in vitro. J Food Sci. 58, 1273-1276. 